\title{
The Impact of Domestic Violence in the Workplace
}

\author{
Results From a Pan-Canadian Survey
}

\author{
C. Nadine Wathen, PhD, Jennifer C. D. MacGregor, PhD, and Barbara J. MacQuarrie, BA
}

\begin{abstract}
Objective: When workers experience domestic violence (DV) at home, impacts are felt in the workplace; however, little research is available on this topic. Methods: We conducted an online survey regarding the impacts of DV at work. Results: A total of 8429 people completed the survey. More than a third of respondents reported experiencing DV; among them, more than a third reported that DV affected their ability to get to work, and more than half reported that it continued at or near work. Most reported that DV negatively affected their performance. Almost all respondents, regardless of DV experience, believed that it impacts victims' work lives. Conclusions: This research identifies the scope and impact of DV on workers and workplaces. The data should assist governments, unions, and employers to enact and evaluate proactive practices to address the impact of DV in the workplace.
\end{abstract}

... we bring to work everything that happens at home. We can't compartmentalize or mentally separate these different aspects of our lives. While it might not technically be the responsibility of the employer or union to provide shelter or assistance for employees being victimized by abusers at home, the workplace is a logical place to provide help, support, and resources for victims of violence.

\section{- Survey participant}

W hen workers are experiencing domestic violence (DV) at home, the impacts are felt in the workplace. A Canadian analysis estimates that employers lose $\$ 77.9$ million yearly as a direct result of DV, and annual personal and system costs attributed to DV across Canadian health and social sectors are estimated in the billions. ${ }^{1,2}$ Reported estimates in the United States and Australia are similarly high. ${ }^{3,4}$

Being in employment is a key pathway for women to leaving a violent relationship. ${ }^{5,6}$ The financial security that employment affords can allow women to avoid isolation and to maintain, as far as possible, their home and standard of living. ${ }^{7}$ At the same time, it is clear that women with a history of DV tend to have a more

From the Faculty of Information \& Media Studies (Drs Wathen and MacGregor) and Centre for Research \& Education on Violence against Women \& Children (Drs Wathen and MacGregor and Ms MacQuarrie), Western University, London, Ontario, Canada.

The authors have no conflicts of interest to declare.

This research has been a collaborative effort between the Centre for Research and Education on Violence Against Women and Children (BM), Western University's Faculty of Information and Media Studies (CNW, JM) and the Canadian Labour Congress. Support was provided by the Canadian Institutes of Health Research-funded Preventing Violence Across the Lifespan (PreVAiL) Research Network (CNW, JM) and the Social Sciences and Humanities Research Council of Canada. We would like to acknowledge the contributions that the Canadian Union of Public Employees (CUPE), the Canadian Union of Postal Workers (CUPW), and the CLC made to translation of the survey, translation of responses, and study recruitment, respectively.

This is an open-access article distributed under the terms of the Creative Commons Attribution-NonCommercial-NoDerivatives 3.0 License, where it is permissible to download and share the work provided it is properly cited. The work cannot be changed in any way or used commercially.

Address correspondence to: C. Nadine Wathen, PhD, Faculty of Information \& Media Studies, Western University, 1151 Richmond St, North Campus Bldg, Room 240, London, ON N6A 5B7, Canada (nwathen@uwo.ca).

Copyright (C) 2015 by American College of Occupational and Environmental Medicine

DOI: 10.1097/JOM.0000000000000499 disrupted work history, are consequently on lower personal incomes, have had to change jobs more often, and are employed at higher levels in casual and part time work than women with no experience of violence. ${ }^{8-11}$ Moreover, an emerging literature demonstrates DV as a form of violence that impacts on, and actually occurs in, the workplace itself. Estimates of DV victims being bothered in some way by their abuser at work (eg, harassing phone calls) range from $36 \%$ to $75 \%$, and most victims report that DV negatively affects their work performance. ${ }^{11}$ Domestic violence can also impact a victim's ability to get to work (eg, through physical restraint), ${ }^{12}$ lead to time off, and, ultimately, job loss for $5 \%$ to $27 \%$ of victims. ${ }^{11}$ Many DV victims also report that their coworkers experience harassment, or even threats or harm from the perpetrator. ${ }^{13,14}$ The majority of research in this area have been conducted with female victims; less data are available about the impact of abuse on men and their work.

Research examining violence from an occupational health and safety perspective tends to focus on violence within the context of nonintimate relationships (ie, "worker-on-worker violence") or between workers and customers, clients, or patients. ${ }^{15,16}$ Nevertheless, DV as a form of workplace violence is increasingly being recognized, and surveys to gather specific data about the prevalence and impact of workplace DV have been conducted in the United States, ${ }^{17}$ the United Kingdom, ${ }^{14}$ New Zealand, ${ }^{18}$ Turkey, ${ }^{19}$ Peru, ${ }^{20}$ and Australia. ${ }^{21}$

This paper reports the main findings of the first large-scale, Canadian research survey on the prevalence and impact of DV in the workplace. More specifically, it provides (1) rates of DV exposure, (2) the occurrence of DV at/near work, (3) the impact of DV on work performance, (4) the impact of DV on victims' ability to get to work, (5) job loss and time off due to DV, (6) the impact of DV on coworkers, (7) beliefs about the impact of DV in the workplace, and (8) gender differences in the impacts of DV at work. The study was conducted in partnership with the Canadian Labour Congress (CLC), which brings together Canada's 34 national and 33 international unions along with 98 provincial and territorial federations of labor, 111 district labor councils, and 12 federations of labor. In total, the organizations represent 3.3 million Canadian workers.

\section{METHODS}

\section{Survey Development}

The survey was based on a 34-item questionnaire used in Australia. ${ }^{21}$ To ensure a robust survey relevant to the Canadian context, a number of steps were taken to adapt the Australian tool. First, we sought input from researchers at the University of New South Wales involved in the Australian study. This was followed by extensive consultation with key stakeholder groups, including the Women's Committee of the CLC, the project Steering Committee and Working Group, experts in specific areas (such as health and legal services), and antiviolence advocates. This led to a number of decisions for adaptation, including the inclusion of demographic questions to mirror, as much as possible, those used in other Canadian national violence and/or labor surveys, especially those conducted by Statistics Canada (eg, using the North American Industry Classification System for work sector). ${ }^{22}$ We also used a definition of DV that included multiple forms of physical, emotional/psychological, and sexual abuse, including controlling behaviors such as financial 
abuse $^{23}$ and asked about its occurrence at various time points, allowing for a more complete picture of its impact, as well as comparability with existing data sets.

The final survey had more than 60 questions; however, the number of questions each participant answered varied depending on their responses (eg, participants with no DV experience were routed past the personal DV questions). At the end of the survey, jurisdiction-specific DV resources (eg, phone numbers and Web sites for shelters) were provided. The survey was prepared in English and pilot tested by the Steering Committee and Working Group, members of the general public, and a DV survivor. It was then translated into French (the other Canadian official language) and reviewed by French-speakers. The survey was prepared for completion, in both languages, on the Fluid Surveys Web survey platform (fluidsurveys. com).

\section{Sampling, Recruitment, and Data Collection}

Individuals 15 years and older who could respond in either English or French were eligible, regardless of their personal experience with DV. The survey was formally launched on December 6, 2013, via media conferences in Ottawa and London, Ontario. In addition to launch-specific activities including significant national media attention, recruitment was conducted by the CLC and its affiliates via posters and bookmarks handed out at events and provided to affiliates for national, regional, and local distribution. Recruitment e-mails were also circulated to and through union officials for distribution through member lists. All materials used the slogan "Can work be safe when home isn't?," noted the CLC-Western University partnership, and provided the Web URL and a QR code to access the survey. In appreciation for their time, participants had the option of entering a draw for a tablet computer; identifying information for draw entries was kept separate from survey responses. The survey period closed on June 6, 2014.

\section{Measures}

The survey began by asking participants to respond to demographic questions including their gender, age, ethnic origins (one or more), place of birth, Aboriginal status, and work-related variables (employment status, union status, sector, hours, and size of workplace). Responses were coded and grouped into major categories. The remaining measures are described in Table 1.

\section{Data Analysis}

Data were analyzed with descriptive statistics and the chisquared analysis using SPSS 21 (IBM, http://www.01-ibm.com/ software/analytics/spss/). Aside from the DV status analyses individuals identifying as transgender or "other" were excluded, due to small sample size, from gender difference analyses.

\section{Ethical Considerations}

Western University's Non-Medical Research Ethics Board approved the project (\#104156).

\section{RESULTS}

\section{Sample Characteristics}

In total, 8429 participants completed the survey, most in English $(n=8051,95.5 \%)$. Key demographic and work characteristics are presented in Table 2 . In addition, most participants listed one or

TABLE 1. Survey Measures

Variable Survey Question(s) Response Options and Coding

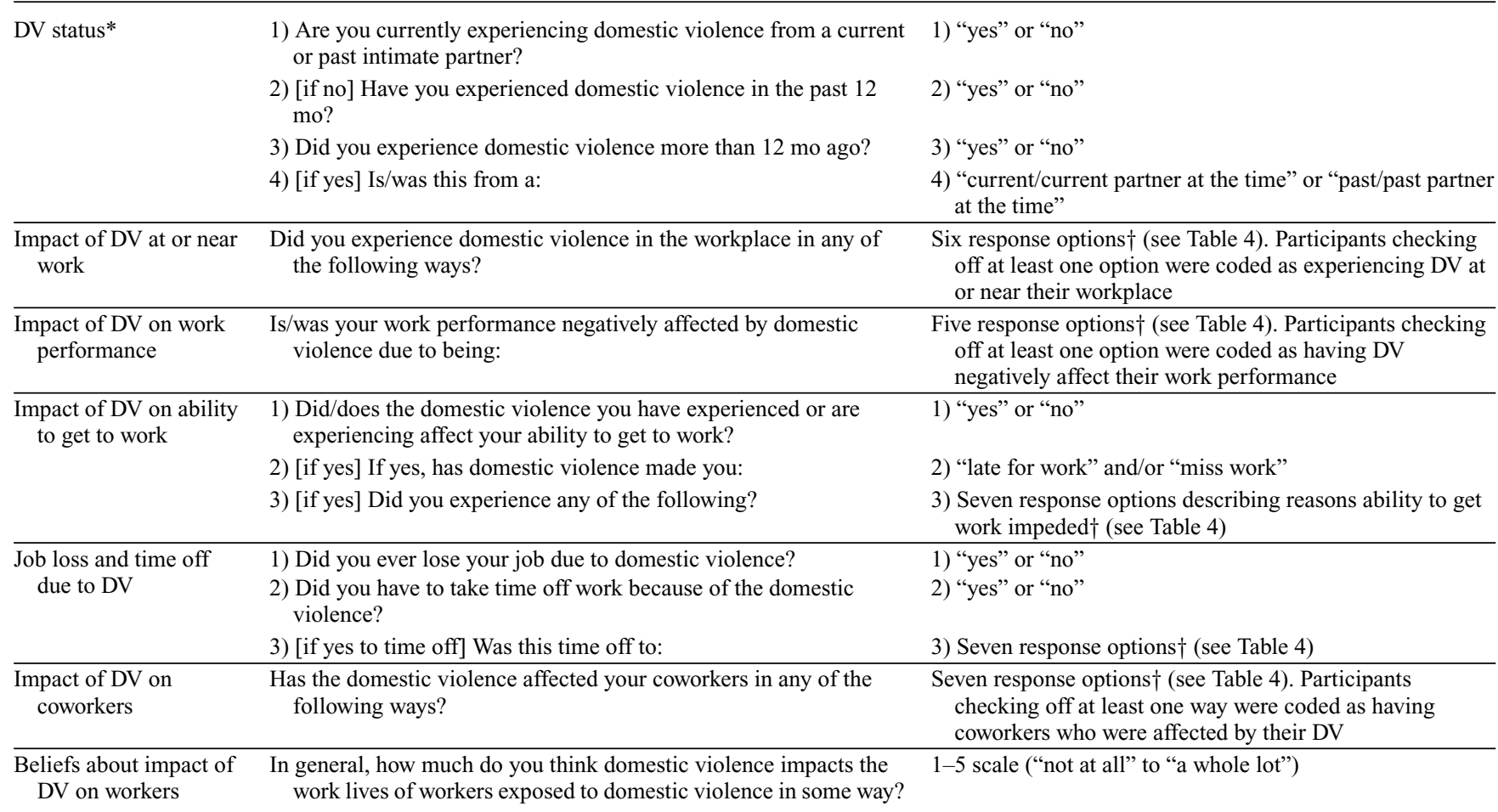

*Participants responding "yes" to at least one DV status question were routed in the survey to respond to questions about how the DV impacted their (and others') work $\dagger$ Participants could choose more than one response option.

DV, domestic violence. 


\begin{tabular}{|c|c|}
\hline Characteristic & $n(\%)$ \\
\hline \multicolumn{2}{|l|}{ Gender } \\
\hline Female & $6,608(78.4)$ \\
\hline Male & $1,723(20.4)$ \\
\hline Transgender/other & $37(0.4)$ \\
\hline No response & $61(0.7)$ \\
\hline \multicolumn{2}{|l|}{ Age, yrs } \\
\hline $15-24$ & $228(2.7)$ \\
\hline $25-34$ & $1,474(17.5)$ \\
\hline $35-44$ & $1,994(23.7)$ \\
\hline $45-54$ & $2,679(31.8)$ \\
\hline $55-64$ & $1,780(21.1)$ \\
\hline $65-74$ & $208(2.5)$ \\
\hline $75+$ & $22(0.3)$ \\
\hline \multicolumn{2}{|l|}{ Employment status } \\
\hline Permanent & $6,834(81.1)$ \\
\hline Temporary/fixed-term contract & $698(8.3)$ \\
\hline Casual/seasonal & $361(4.3)$ \\
\hline Unemployed & $125(1.5)$ \\
\hline Other (eg, retired and on leave) & $369(4.4)$ \\
\hline No response & $42(0.5)$ \\
\hline \multicolumn{2}{|l|}{ Union status } \\
\hline Unionized & $6,862(81.4)$ \\
\hline Nonunionized & $1,471(17.5)$ \\
\hline No response & $96(1.1)$ \\
\hline \multicolumn{2}{|l|}{ Work week } \\
\hline Full-time ( $30 \mathrm{~h}$ or more per week) & $7,180(85.2)$ \\
\hline Part-time (less than $30 \mathrm{~h}$ per week) & $1,141(13.5)$ \\
\hline No response & $108(1.3)$ \\
\hline \multicolumn{2}{|l|}{ Size of workplace } \\
\hline Less than 20 workers & $1,597(18.9)$ \\
\hline 20-99 workers & $2,690(31.9)$ \\
\hline $100-500$ workers & $1,932(22.9)$ \\
\hline More than 500 workers & $2,112(25.1)$ \\
\hline No response & $98(1.2)$ \\
\hline
\end{tabular}

two ethnic origins, with the most common categories being British, European, and North American. The majority of participants were born in Canada $(n=7394,87.7 \%)$, and $4.7 \%(n=396)$ identified as an Aboriginal/Indigenous person of Canada. Most of the sample reported working (now or in their last job) in the educational $(28.2 \%)$ or health care and social assistance $(23.8 \%)$ sectors. All other sectors were less than $9 \%$ each, and $8 \%$ indicated "other."

\section{Status}

Overall, $33.6 \%$ of the sample reported ever experiencing DV $(n=2831), 6.5 \%(n=547)$ were currently experiencing DV, $3.3 \%$ $(n=277)$ in the last 12 months (but not currently), and 31.5\% $(n=$ 2654) experienced it more than 12 months ago (see Fig. 1). Among those currently experiencing DV, $41.5 \%(n=227)$ were being abused by a current partner, and $56.3 \%(n=308)$ by a past partner $(2.2 \%$, $n=12$ did not respond). Among those with DV experience in the last 12 months, $52.4 \%(n=145)$ had been abused by a current partner at the time and $35.4 \%(n=98)$ had been abused by a past partner at the time $(12.3 \%, n=34$ did not respond). Among participants who experienced DV more than 12 months ago, $45.3 \%(n=1203)$ were abused by a current partner at the time and $50.6 \%(n=1344)$ by a past partner at the time $(4.0 \%, n=107$ did not respond). Most participants with DV experience had experienced it more than 12 months ago only $(64.3 \%, n=1820)$. Women and transgender individuals were more likely than men to report lifetime, current, and 12-month or more DV experience, but not DV in the last 12 months (see Table 3 and Fig. 1).

In the following analyses, we use the variable "lifetime DV," which includes participants who indicated experiencing DV at any of the three time points.

\section{Impact of DV At or Near Work}

More than half $(53.5 \%, n=1515)$ of participants with any lifetime DV experience reported that the violence continued at or near their workplace. Most commonly this was in the form of abusive phone calls or text messages (Table 4). Other work-related DV included threats (eg, abuser threatened to come to the workplace) and other emotional abuse (eg, telling victim that coworkers do not respect her or him). Gender only marginally predicted whether the DV continued at or near the workplace, although the pattern was such that men were less likely than women to report the DV following them to work (Table 5).

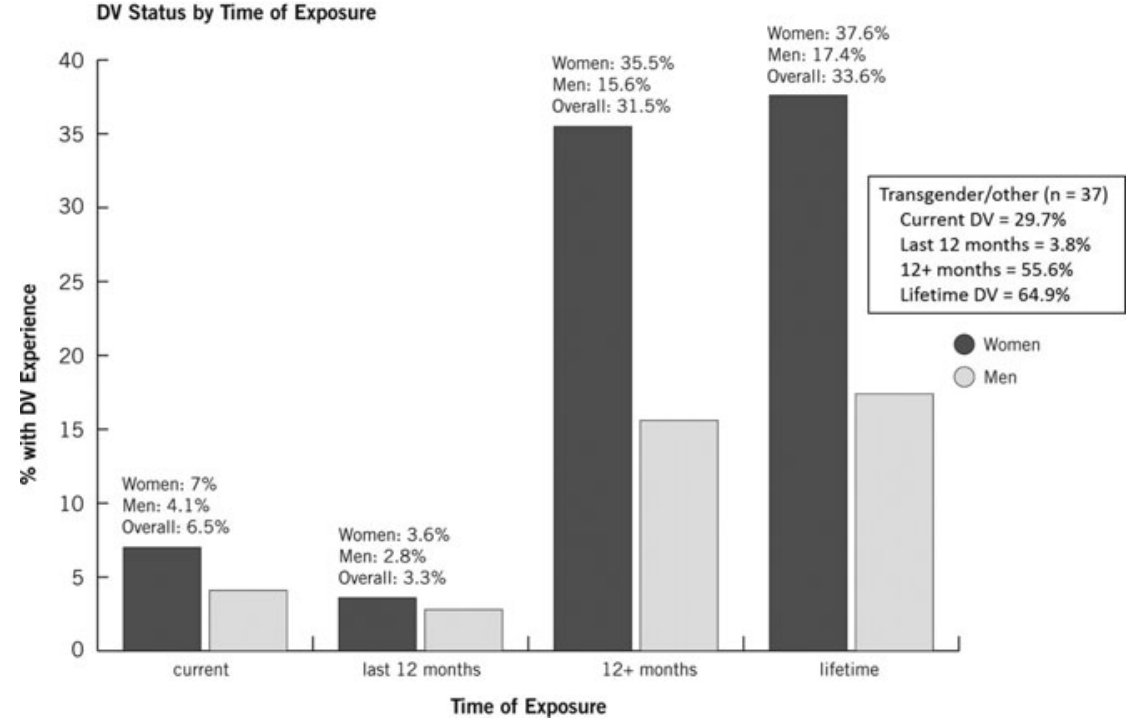

FIGURE 1 . DV status by time of exposure. 
TABLE 3. Prevalence of DV by Gender

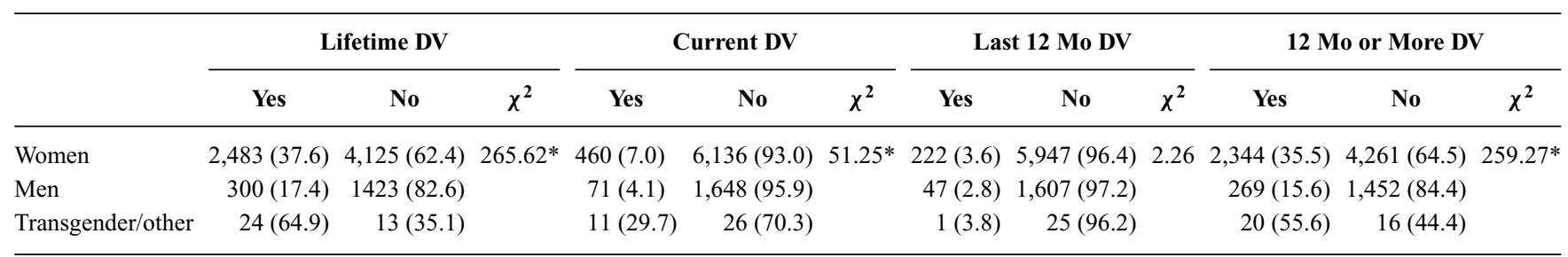

${ }^{*} P<0.001$.

DV, domestic violence.

TABLE 4. The Impacts of DV in the Workplace

$n(\%)$

The impact of DV at or near work

Abusive phone calls or text messages

Abusive e-mail messages

Abuser physically came to the workplace

Abuser stalked or harassed near the workplace

Abuser contacted coworkers/employer (about victim)

Other

The impact of DV on work performance

Work performance negatively impacted due to being:

Distracted (eg, by stress, abusive phone calls, and e-mails)

Tired (eg, due to sleep deprivation from the DV)

Unwell (eg, anxiety, depression, and headache from the DV)

Injured (from the DV)

Other

Reasons for taking time off due to DV

Attend criminal court

Attend family court

Attend appointments related to the DV (eg, police and lawyer)

Attend counseling related to the DV

Deal with health/medical issues related to the DV

Deal with accommodation issues related to the DV (eg, had to move house)

Other

The impact of DV on coworkers

They were harmed or threatened

They had to deal with frequent phone calls, messages, or e-mails from the abuser

They were stressed or concerned about the situation

Their work was affected (eg, increased workload and changed schedule)

The DV caused conflict and tension between you and your coworkers (eg, due to changes to workloads, deadlines, and shared projects)

Other

I do not know if the DV affected them

$79(2.8)$

$667(23.6)$

DV, domestic violence.

\section{Impact of DV on Work Performance}

Most participants $(81.9 \%, n=2319)$ with DV experience reported that it negatively affected their work performance, most commonly due to being distracted or feeling tired and/or unwell (Table 4). Most participants whose work performance was negatively $443(15.6)$ $515(18.2)$ $580(20.5)$ $411(14.5)$ $61(2.2)$

$1,869(66.0)$

$1,758(62.1)$

$1,756(62.0)$

453 (16.0)

124 (4.4)

$221(19.7)$

$252(22.5)$

395 (35.3)

$545(48.7)$

$750(67.0)$

464 (41.5)

$125(11.2)$

96 (3.4)

$292(10.3)$

819 (28.9)

314 (11.1)

273 (9.6) affected checked off more than one way $(80.2 \% ; n=1859)$. Men were less likely to report negative effects on their work performance (Table 5).

\section{Impact of DV on Ability to Get to Work}

Among participants with any lifetime DV experience, $38.0 \%$ $(n=1077)$ had their ability to get to work impeded by DV $(58.0 \%$, $n=1641$ did not, and $4.0 \%, n=113$ did not respond). Of these, $12.5 \%(n=135)$ had been made late for work, $30.0 \%(n=323)$ had been made to miss work, and $51.4 \%(\mathrm{n}=554)$ had experienced both $(6.0 \%, n=65$ did not indicate how their ability to get to work was affected). Men were less likely than women to report DV-specific barriers to getting to work (see Table 5).

\section{Job Loss and Time Off Due to DV}

Of those with DV experience, $8.5 \%(n=242)$ reported having lost a job due to the violence, with men less likely to report this outcome (Table 5). In addition, 39.5\% $(n=1119)$ took time off because of the DV; again, men were less likely to report this (Table 5). The most common reason was dealing with health/medical issues related to the violence, followed by attending DV-related counseling (Table 4).

\section{Impact of DV on Coworkers}

Of those with DV experience, $37.1 \%(n=1051)$ reported that the DV impacted their coworkers, with almost half $(49.0 \%, n=515)$ indicating multiple impacts; there was no effect of gender $\left(\chi^{2}=\right.$ $2.68, P=0.10)$. The most common was coworkers being stressed or concerned about the situation (Table 4).

\section{Beliefs About Impact of DV on Workers}

Overall, most participants believed DV had at least some impact on workers $(91.5 \%, n=7711$; Fig. 2$)$. Men believed DV to have a smaller impact on workers $(\mathrm{M}=4.08, \mathrm{SD}=0.87)$ than did women $(\mathrm{M}=4.30, \mathrm{SD}=.76), F_{1,7665}=94.70, P<0.001$.

\section{DISCUSSION}

Consistent with national population-based surveys, ${ }^{24,25}$ more than a third of respondents, most of whom were employed at the time of completing the survey, reported personal experience with DV at some point in their life. This was higher for women and among the small subsample of gender diverse people. Among those who had ever experienced DV, more than a third reported that the violence affected their ability to get to work, and more than half reported that it continued at the workplace in some way, for example, harassing phone calls from the abuser and stalking. These rates are comparable with ones found by similar large-scale surveys conducted in Australia and New Zealand. ${ }^{18,21}$ Not surprisingly, the vast majority who had experienced violence reported that it negatively affected their work performance, for example, due to being distracted, tired, or unwell. These findings are also consistent with previous rates of, and the reasons for, negative effects on performance. ${ }^{11,14}$ Overall, 


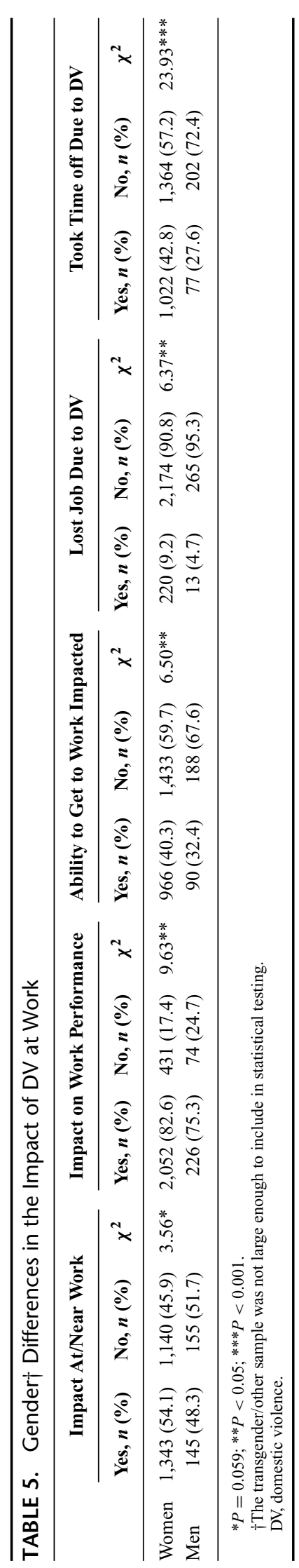

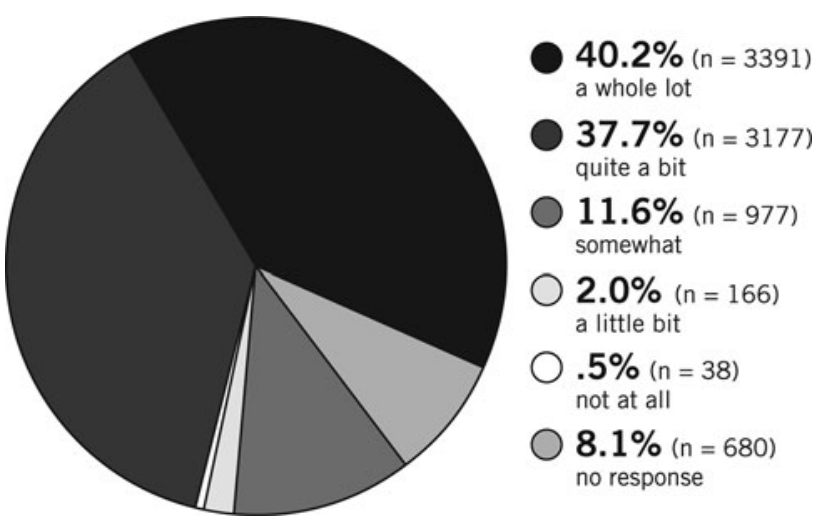

FIGURE 2. Beliefs about impact of DV on workers.

men tended to be less likely than women to experience the negative consequences associated with DV at the workplace.

The vast majority of respondents, whether or not they had personally experienced DV, believed that it impacts the work lives of those experiencing abuse "quite a bit" or "a whole lot," and while there were slight differences by gender, it is clear that the impact of DV in the workplace is seen by most of these Canadian workers, as with other national surveys, ${ }^{18,21}$ as a significant issue.

The evidence base on the impacts of DV in the workplace is only beginning to emerge, and the majority of studies to date have been conducted in the United States. Some of this research is qualitative in nature ${ }^{26,27}$ and, although valuable in its own right, is not directly comparable with our quantitative findings. We are aware of no research that is directly comparable with our gender analyses of the impacts of DV at work. Nevertheless, overall, our findings are consistent with previous research demonstrating that DV has a significant impact on workers and workplaces ${ }^{11}$ and is therefore a significant form of "workplace violence." Although the economic costs of DV for victims, employers, and society are very high, ${ }^{1}$ and demand attention from policymakers and the public alike, the personal costs of DV must not be ignored. Our findings contribute to the growing literature establishing DV as not just a "domestic" issue, but one that extends far beyond the home-into victims' work lives and even the lives of their coworkers.

Nevertheless, employers have been slow to respond with policies that would protect workers. The US Bureau of Labor Statistics ${ }^{28}$ reports that about $15 \%$ of employers have such a policy and $4 \%$ of employers offer training on DV prevention. Legislative and executive directives to develop model policies and promote best practices particularly in the public sector have been implemented in the United States and the United Kingdom. Recently, there has also been growth in US state and local legislation and administrative regulations that offer work leave for victims, aim to reduce DV-related employment discrimination, and increase awareness and safety in the workplace. ${ }^{7,29}$ In Australia, since 2010 and based primarily on results of the previously described survey, ${ }^{21}$ clauses providing paid leave and other entitlements to victims of DV were included in unionnegotiated enterprise agreements. More than a million workers are now covered by collective agreements that offer protections to workers experiencing DV. ${ }^{30}$

In Canada, DV protections for workers are primarily provided through Occupational Health and Safety legislation. Most jurisdictions have a "general duty provision" that requires employers to take all reasonable precautions to protect the health and safety of employees. The presence of DV-specific legislation differs by province. In general, countries lack national-level strategies to address DV in the workplace and there is currently no international labor standard to address this issue. At the workplace level, there is an urgent 
need to develop and evaluate specific interventions for victims and perpetrators.

\section{Limitations and Future Research}

To our knowledge, this is the largest data set exploring the impact of DV on workers and workplaces in Canada and internationally. Nevertheless, there are some limitations. Sampling was not random, and although Canadians from all provinces/territories participated, the sample is not proportionally representative of each jurisdiction's population - for example, Ontario and British Columbia were overrepresented, whereas Quebec and the Atlantic provinces were underrepresented. Nevertheless, the very large sample size and the consistency of the rates of DV in the sample with national population-based surveys are indicators of validity and reliability. The sample was also atypical compared with many violence-related studies in that most respondents were employed, and likely to have higher incomes; however, we see this as adding new knowledge to the field, underscoring the fact that DV is a problem cutting across socioeconomic boundaries. ${ }^{31-34}$ Given the recruitment strategy, most respondents were unionized workers, and many of these were from the health and education sectors; more research in nonunionized settings and other sectors is needed. Finally, the small number $(n=37,0.4 \%)$ of gender diverse individuals in the sample prevented their inclusion in the gender analyses of the impacts of DV in the workplace. This is unfortunate given the very high rates of DV and impacts reported by this subgroup, and the lack of existing evidence. Additional research in this area is an urgent priority.

\section{CONCLUSIONS}

By identifying the scope and impact of DV on workers and workplaces, this research calls attention to an important and widespread form of workplace violence; however, it is only a first step. Immediate next steps include encouraging use of these results by governments, unions, and employers to establish and evaluate proactive practices to address the impact of DV at work, especially in terms of educating managers, supervisors, and workers about DV in the workplace and developing and testing specific protocols and tools to protect and support victims and intervene with perpetrators.

Improving the workplace response to DV will require a multipronged approach by legislators, employers, unions, and advocates to protect and support victims and assist perpetrators in changing their behavior. Ultimately, preventing DV and its consequences is a collective social challenge; one place that positive change can happen-for victims, offenders, and employers-is the workplace. These survey results will help us take steps in the right direction.

\section{REFERENCES}

1 Zhang T, Hoddenbagh J, McDonald S, et al. An Estimation of the Economic Impact of Spousal Violence in Canada, 2009. Ottawa, ON: Department of Justice Canada, Research and Statistics Division; 2012.

2. Varcoe C, Hankivsky O, Ford-Gilboe M, et al. Attributing selected costs to intimate partner violence in a sample of women who have left abusive partners: a social determinants of health approach. Can Pub Policy. 2011;37:359-380.

3. National Center for Injury Prevention and Control. Costs of Intimate Partner Violence Against Women in the United States. Atlanta, GA: Centers for Disease Control and Prevention; 2003.

4. National Council to Reduce Violence Against Women and their Children. The Cost of Violence Against Women and their Children. Australia: Australian Government, Department of Families, Housing, Community Services and Indigenous Affairs. Available at: https://www.dss.gov.au/sites/default/files documents/05_2012/vawc_economic_report.pdf. Published 2009. Accessed January 13, 2015.

5. Patton S. Pathways: How Women Leave Violent Men. Hobart, Tasmania: Government of Tasmania; 2003.
6. Rothman EF, Hathaway J, Stidson A, et al. How employment helps female victims of intimate partner violence: a qualitative study. J Occup Health Psychol. 2007;12:136-143.

7. Widiss D. Domestic violence and the workplace: the explosion of state legislation and the need for a comprehensive strategy. Fla State Univ Law Rev. 2008;35:669-728

8. Adams AE, Tolman RM, Bybee D, et al. The impact of intimate partner violence on low-income women's economic well-being: the mediating role of job stability. Violence Against Women. 2013;18:1345-1367.

9. Crowne SS, Juon H, Ensminger M, et al. Concurrent and long-term impact of intimate partner violence on employment stability. J Interpers Violence. 2011;26:1282-1304

10. Moe AM, Bell MP. Abject economics: the effects of battering and violence on women's work and employability. Violence Against Women. 2004;10:29-55.

11. Swanberg JE, Logan T, Macke C. Intimate partner violence, employment, and the workplace. Trauma Violence Abuse. 2005;6:286-312.

12. Galvez G, Mankowski ES, McGlade MS, Ruiz ME, Glass N. Work-related intimate partner violence among employed immigrants from Mexico. Psychol Men Masc. 2011;12:230-246.

13. Logan TK, Shannon L, Cole J, et al. Partner stalking and implications for women's employment. J Interpers Violence. 2007;22:268-291.

14. Trades Union Congress. Domestic Violence and the Workplace: A TUC Survey Report. London, UK: Trades Union Congress; 2014.

15. Peek-Asa C, Casteel C, Rugala E, et al. Workplace violence investigations and activation of the threat management teams in a multinational corporation. J Occup Environ Med. 2013;55:1305-1311.

16. Tiesman HM, Hendricks S, Konda S, et al. Physical assaults among education workers: findings from a statewide study. JOccup Environ Med. 2014;56:621627.

17. Corporate Alliance to End Partner Violence. Corporate Leaders and America's Workforce on Domestic Violence. Available at: http://www.ncdsv.org/images/Corporate\%20Leaders\%20and\%20America\% 27s\%20Workforce\%20on\%20DV\%20Summary_9-25-07.pdf. Published 2007. Accessed January 13, 2015.

18. Rayner-Thomas MM. The Impacts of Domestic Violence on Workers and the Workplace. Auckland, NZ: The University of Auckland; 2013.

19. Corporate Governance Forum of Turkey. Domestic Violence Against WhiteCollar Working Women in Turkey: A Call for Business Action. Istanbul, Turkey: Sabanci University; 2014.

20. ValeraLoza D, Brendel C, Gurtner S. Violence Against Women and its Financial Consequences for Business in Peru. Peru: University of San Martin de Porres; 2014.

21. McFerran L. National Domestic Violence and the Workplace Survey (2011). Australia: Australian Domestic and Family Violence Clearinghouse, Australian Government; 2011.

22. Statistics Canada. North American Industry Classification System (NAICS) Canada 2012. Available at: http://www23.statcan.gc.ca/imdb/p3VD. pl?Function $=$ getVDPage $1 \& \mathrm{db}=\mathrm{imdb} \& \mathrm{dis}=2 \& \mathrm{adm}=8 \& \mathrm{TVD}=118464$. Accessed August 28, 2014.

23. Krug EG, Dahlberg LL, Mercy JA, et al eds. World Report on Violence and Health. Geneva, Switzerland: World Health Organization; 2002.

24. Rodgers K. Wife assault: the findings of a national survey. Juristat. 1994;14:121.

25. Statistics Canada. Family Violence in Canada: A Statistical Profile. Canadian Centre for Justice Statistics. Available at: http://www.statcan.gc.ca/pub/ 85-224-x/85-224-x2010000-eng.pdf. Published 2011. Accessed January 14, 2015.

26. Swanberg JE, Macke C. Intimate partner violence and the workplace: consequences and disclosure. Affilia. 2006;21:391-406.

27. Wettersten KB, Rudolph SE, Faul K, et al. Freedom through self-sufficiency: a qualitative examination of the impact of domestic violence on the working lives of women in shelter. J Couns Psychol. 2004;51:447-462.

28. Bureau of Labor Statistics. Survey of Workplace Violence Prevention, 2005. Washington, DC: US Department of Labor, Bureau of Labor Statistics; 2006.

29. Swanberg JE, Ojha MU, Macke C. State employment protection statutes for victims of domestic violence: public policy's response to domestic violence as an employment matter. J Interpers Violence. 2014;27:587-619.

30. Baird M, McFerran L, Wright I. An equality bargaining breakthrough: paid domestic violence leave. $J$ Ind Relat. 2014;56:190-207.

31. Lloyd S. The effects of domestic violence on women's employment. Law Policy. 1997;19:139-167.

32. Statistics Canada. Family Violence in Canada: A Statistical Profile. Canadian Centre for Justice Statistics. (Catalogue no. 85-224). Available at: http:// 
www.fact.on.ca/Info/dom/stat2000.pdf. Published 2000. Accessed January $14,2015$.

33. Statistics Canada. Measuring Violence Against Women: Statistical Trends. (Catalogue no. 85-570-XIE). Available at: http://ywcacanada.ca/data/ research_docs/00000043.pdf. Published 2006. Accessed January 14, 2015.
34. Statistics Canada. Measuring Violence Against Women: Statistical Trends. Canadian Centre for Justice Statistics. Juristat (Catalogue no. 85-002-X). Available at: http://www.statcan.gc.ca/pub/85-002-x/ 2013001/article/11766-eng.htm. Published 2013. Accessed January 14, 2015 . 